Original article

\title{
Patients' opinion of pharmacists and their roles in health care system in Pakistan
}

\author{
Muhammad Umair Khan ${ }^{\mathrm{a}, *}$, Abdul Nabeel Khan ${ }^{\mathrm{a}}$, Farrukh Rafiq Ahmed ${ }^{\mathrm{a}}$, Zeeshan Feroz ${ }^{\mathrm{b}}$ \\ Syed Ata Rizvi ${ }^{\mathrm{a}}$, Shahjahan Shah ${ }^{\mathrm{c}}$, Rahat Hussain ${ }^{\mathrm{d}}$, Zeeshan Adil ${ }^{\mathrm{e}}$ \\ a Ziauddin College of Pharmacy, Ziauddin University, Karachi 75600, Pakistan \\ ${ }^{\mathrm{b}}$ Department of Basic Sciences, College of Science and Health Professions, King Saud bin Abdulaziz University for Health Sciences, Riyadh, Saudi Arabia \\ ${ }^{\mathrm{c}}$ Department of Pharmaceutics, University of Karachi, Karachi 75270, Pakistan \\ ${ }^{\mathrm{d}}$ Department of Pharmaceutical Chemistry, University of Karachi, Karachi 75270, Pakistan \\ ${ }^{\mathrm{e}}$ College Business Management, Institute of Business Management, Karachi 75190, Pakistan
}

\section{A R T I C L E I N F O}

\section{Article history:}

Received 24 June 2013

Accepted 9 August 2013

Available online 8 September 2013

\section{Keywords:}

Pharmacist

Patient

Perception

Attitude

Health care

\begin{abstract}
A B S T R A C T
Background: Pharmacist-patient association is a decisive component in improving health care system. To offer patient centred services, the pharmacists need to fully understand patients' perspectives and views to meet their needs and expectations.

Purpose: To evaluate patients' perception of pharmacist and pharmacy practice in Pakistan.

Methods: A cross sectional study was conducted between July and September 2012 on patients attended out-patient clinic in a teaching hospital of Pakistan. By using raosoft sample size calculator, questionnaires were distributed to a sample of 376 patients. Questionnaire included different section which evaluated the demographic information, frequency and reason of interaction, perception and choice of pharmacy. Statistical analysis was done by using SPSS (v.17).

Results: A total of 301, out of 376, surveys returned giving a response rate of $80 \% .51 .8 \%(n=156)$ participants interacted with pharmacist on regular basis. The major reasons of interaction were drug alternative and drug availability queries (41.5\%, $n=125$ and $26.2 \%, n=79)$. The finding also showed that $84.1 \%$ ( $n=253$ ) of participants agreed that pharmacists are important part of health care system. Interestingly, all the patients $(n=301)$ either agreed or strongly agreed that discount was the major influencing factor on their choice of pharmacy.

Conclusion: The patients' perception of pharmacist in Pakistan was generally positive but their understanding is very primitive as majority of the patients are unaware of pharmaceutical care services. However, they are more devoted to witness such services being practiced in Pakistan. This transition in practice could be brought into certainty by proactive involvement of pharmacists in community setup.

Copyright (c) 2013, InPharm Association, Published by Reed Elsevier India Pvt. Ltd. All rights reserved.
\end{abstract}

\section{Introduction}

In recent times, the profession of pharmacy in Pakistan has undergone a process of transition from product oriented to patient centred pharmaceutical care. This transition is supported by the transformation of bachelors of pharmacy degree to doctor of pharmacy degree, which has also shifted the focus of pharmacist from dispensing of drugs to clinical related activities like designing and monitoring of pharmacotherapeutics regimens, patient education and solution of drug related problems. ${ }^{1}$ These changes are great sign for health care system of Pakistan as newly defined

\footnotetext{
* Corresponding author.

E-mail address: umair104@yahoo.com (M.U. Khan).
}

pharmacy services would be helpful in establishment of effective pharmaceutical care in the country. However, the perception of patients regarding the role of pharmacist is still not completely understood.

Patient satisfaction is an important measure of how well the services are provided. ${ }^{2}$ Many studies have been conducted around the world which has evaluated the perception of patients regarding the role of pharmacist and the profession of pharmacy practice. One study reported that patient and pharmacists have contradictory beliefs about potential pharmacy services. Findings revealed that patients had negative perceptions regarding the role of pharmacy services. ${ }^{3}$ In another study patients were dissatisfied with the role of pharmacist as an education provider and perceived pharmacist as a poor counsellor concerning asthma medications in the community pharmacy settings. ${ }^{4}$ 
Literature have revealed that patients' knowledge and expectation of pharmacist varies considerably and is influenced by many factors as Wiederholt and Rosowski supported the notion that the type of pharmacy practice site can influence patients' expectation. ${ }^{5}$ Another study reported a significant difference in expectations for pharmaceutical services based on age. ${ }^{6}$

Many patients expect pharmacist to share responsibility with physician for providing risk assessment and risk management. ${ }^{7} \mathrm{Re}-$ searchers believed that the reason of negative perception of patients regarding the role of pharmacist is the lack of communication and the lack of awareness. The first and second most frequent barriers as reported by patients were fear/intimidation and their apprehension about the knowledge of pharmacist to answer their questions. ${ }^{8}$

Pharmacists usually enjoy a privileged honour among professions. Through public polls for years, pharmacists are enjoying to be at finished or near the top of the most loyal occupations. Moreover, study has revealed that the public deems a pharmacist's personal qualities, proficiency in communication, rationality and impression is trustworthy. However, pharmacist's ideal role doesn't inevitably translate into an exact portrayal with this level of trust. An obstacle to expand professional services by pharmacists may occur in some cases, when patients underestimate the critical functions of pharmacists. ${ }^{9}$ In community pharmacies, pharmacistpatient communication study has shown that it occurs as a one way communication as patients do not participate by querying pharmacist. ${ }^{10}$ People may not always identify how pharmacists work or understand the part they play in assuring safe medication use. ${ }^{11}$ In the 1990s researchers stated that 40 to 67 percent of patients who obtain prescriptions in pharmacies do not usually communicate with their pharmacist regarding their health related conditions of medications. A marketing overview would postulate, however that patient counselling might not be rendered regularly or comprehensively due to absence of demand for these services. ${ }^{12}$ Pharmacists have reported that, they are responsible for patients' counselling but they first determine the amount and content of counselling to offer patients according to their desire and acceptance of it. Pharmacists, patients, and pharmacy environments all are necessary for patient counselling rendered by pharmacists. Pharmacist's role in many patients' view is the one that fits within their total health care that is supervised and determined by their physician. Patients should be informed more about what their pharmacist is efficient of doing in the health care system and how pharmacist services can add worth to a patient's health care of what their physician can provide alone. Only then that pharmacy practice can be transformed from a product-oriented practice to a patient oriented profession. ${ }^{13}$ Since not much research has been done in past regarding the evaluation of opinion and the knowledge of patients about the role of pharmacist, this study was conducted to better understand patients' perception of pharmacist and pharmacy practice in Pakistan.

\section{Methodology}

\subsection{Study design and setting}

This study was based on a cross sectional survey which was conducted for a period of three months from July 2012 to September 2012 on patients attended out-patient clinic in a teaching based private sector hospital of Karachi, Pakistan.

\subsection{Sample size and sampling technique}

Sample size was calculated as 376 while keeping the margin of error as $5 \%$, confidence level as $95 \%$, population size as 20,000 and response distribution as $50 \%$ by using raosoft sample size calculator. ${ }^{14}$ Convenient sampling technique is used to select a sample.

\subsection{Study instrument development}

The questionnaire used in this study was adapted from the research conducted in Saskatchewan; Canada. ${ }^{9}$ After making necessary amendments, the questionnaire was validated in 2 steps. In first step, the questionnaire was sent to researchers and professionals of pharmacy colleges in Karachi and was asked to give their expert opinion on the questions with respect to their relativity, simplicity and importance. In second step, the same procedure is repeated by selecting a small group of participants $(n=25)$. These participants gave their suggestions on making the questionnaire more brief and simple. After a series of group discussion, necessary changes were made and the questionnaire was finalized.

\subsection{Study instrument distribution}

The questionnaires were hand delivered by the data collection team and the purpose of the study was also informed to the participants. The questionnaire was distributed in five parts. The first part tells about the demographic information. The second part identifies the frequency of interaction of patients with pharmacist followed by the classification of reasons of interaction which makes the third part of this study instrument. The next part focuses on the perception of patients regarding the role of pharmacist. And, the last part of the questionnaire determines the factors which affect patients' choice of pharmacy.

The demography represents information like age, gender, education and working status of study participants. Each section of the questionnaire included a set of statements in which the respondents were asked to indicate their level of agreement especially in section four and five where 4 point Likert scale was used to avoid the confusion with the neutral responses.

\subsection{Statistical analysis}

The data analysis was done using Statistical Package for Social Sciences (SPSS version 17, SPSS Inc., Chicago, IL, USA). Descriptive analysis was conducted. The results of each item on the questionnaire were reported, as percentages and frequencies. Chi-square test was applied to assess the important relation between the independent variables (age, gender, education and working status) and dependent variables (perception and choice of pharmacy). Statistical significance was accepted at $P$ value of $<0.05$.

\subsection{Ethical approval}

The study protocol was approved by the institutional research ethics committee. Furthermore, written consent was obtained from the respondents prior to participation in the study.

\section{Results}

Out of the three hundred fifty questionnaires distributed, three hundred and one questionnaires were returned back by the respondents giving the response rate of $86 \%$. The demographic information shows that male participants were slightly more in numbers as compared to their female counterparts (Table 1 ).

The majority of the participants, $79.9 \%(n=265)$ were less than 40 years of age with the mean age of 37.4 years (S.D. \pm 8.03 years). $32.8 \%(n=109)$ of participants were at least graduated however $33.7 \%$ ( $n=112$ ) of the participants were unemployed. The number of patients who never or rarely interacted with the pharmacist was 
Table 1

Patients' demographic information.

\begin{tabular}{lc}
\hline Variable & Frequency (percentage) \\
\hline Gender: & $162(53.8)$ \\
Male & $139(46.2)$ \\
Female & \\
Age: & $130(43.1)$ \\
$<30$ & $135(44.8)$ \\
$31-40$ & $20(6.6)$ \\
$41-50$ & $16(5.3)$ \\
$>50$ & \\
Education & $48(15.9)$ \\
Never went to school & $21(6.9)$ \\
Below Matriculation & $65(21.5)$ \\
Secondary school & $58(19.2)$ \\
Higher secondary school & $109(36.2)$ \\
Graduation and above & \\
Occupation: & $15(4.9)$ \\
Business & $94(31.2)$ \\
Government job & $80(26.5)$ \\
Private job & $112(37.2)$ \\
Unemployed &
\end{tabular}

the highest as shown in Table $2(48.2 \%, n=145)$. While those who interacted, the frequency of interaction was mainly once a week as answered by $47.8 \%(n=144)$ of the patients. The major reason of interaction of patients with pharmacist as indicated in Table 3 was about drug availability and drug alternative queries $(26.2 \%, n=79$ and $41.5 \%, n=125$ ).

The overall perception of patients about pharmacist was on the positive side as $84.1 \%(n=253)$ patients agreed and strongly agreed that pharmacists are the important part of the health care team. Significant difference was also spotted on this question with respect to the education of the participants $(P=0.001)$. However, $60.5(n=182)$ denied that pharmacist is more expert on drugs as compared to physician. It was also noted that majority of the patients $(96.7 \%, n=291)$ were willing to spent time required by pharmacist for counselling. Significant difference was also found among participants on the basis of education and occupation as shown in Table $4(P=0.037$ and $P=0.039)$.

When queried about the factors which influenced their choice of pharmacy, it was found that all the participants $(100 \%, n=301)$ agreed and strongly agreed that discount was the major factor which influenced their selection of pharmacy followed by the location factor where majority of the participants expressed that they prefer to go to the pharmacy nearer to their house $(95.3 \%$, $n=287$ ). On the contrary, patients were least bothered to visit the pharmacy where pharmacist inform them about related side effects or counsel them about any drug related problems as mentioned in Table $5(41.5 \%, n=125)$.

\section{Discussion}

In Pakistan community pharmacy practice is still underdeveloped due to scarcity of community pharmacists in the society and this vacuum is filled in mostly by businessmen who open and run retail drug stores. ${ }^{15}$ On the other hand with the opening of new pharmacy colleges and subsequently the growing number of

Table 2

Frequency of interaction.

\begin{tabular}{lc}
\hline Variable & Frequency (percentage) \\
\hline Frequency of interaction: & \\
Never/rarely & $145(48.2)$ \\
Once a week & $144(47.8)$ \\
Once daily & $12(4)$ \\
\hline
\end{tabular}

Table 3

Reasons for interaction.

\begin{tabular}{lc}
\hline Variable & Frequency (percentage) \\
\hline Reason for interaction: & \\
Drug availability queries & $79(26.2)$ \\
Drug alternative queries & $125(41.5)$ \\
Drug dosage queries & $43(14.3)$ \\
Side effects queries & $54(17.9)$ \\
Drug interaction queries & $0(0)$ \\
\hline
\end{tabular}

pharmacy students graduating each year in the country and specifically in the city of Karachi, where this study was conducted, there has been an increasing trend of pharmacists being attracted to community pharmacy practice, owing to job saturation in the industrial sector. ${ }^{16}$ In the recent years there have been several new pharmacies opened across the city along with various hospital pharmacy setups where round the clock pharmacy services are available to the patients and public. In this context it is worth considering getting to know the perception of general public towards a pharmacist, pharmacy services and reasons for choosing a particular pharmacy. During the survey most of the patients were found to be males ( $49 \%, n=162)$ and below the age of $40(80 \%$, $n=265$ ). It is important to know that the education of over $60 \%$ $(n=192)$ of the participants was merely either higher secondary education (grade 12) or below which might help justifying the reflection of confusion (as can be seen from the answers to the questions) among the participants in understanding the proper role of a pharmacist, his or her qualification and the functions of a pharmacy, specially as this speciality (community) of the profession is still in its infancy and the traditional view is overwhelmingly of a drug store run by businessmen who may gain good knowledge about drugs after some experience of selling drugs. ${ }^{17}$

The patients' perception regarding the pharmacist's qualification and knowledge, his or her role in a community health care setup, authorities and duties were assessed by means of total 11 items in the questionnaire. Responding to the items related to pharmacists qualification, knowledge and over all pharmacy being a profession, most of the respondents (84\%) strongly agreed or agreed to the point that pharmacists are professionals just like other professionals in a $(n=253)$ health care setup, however their perception regarding their qualification was confusing as the matter of fact that over $78 \%(n=233)$ respondents believed that they are just businessmen who open the drug store and run the retail pharmacy. This viewpoint is strictly in conjunction with the reported literature about the fact that majority of the persons running pharmacies are either pharmacy technicians or just business persons. The perception regarding the duties of pharmacist was limited which can be clearly observed by the fact that overwhelming majority $(86 \%, n=257)$ did not know that what a pharmacist does beside counting the drugs and dispensing them and almost half of the respondents who interacted with a pharmacist on daily ( $4 \%, n=12$ ) or weekly $(48 \%, n=144)$ basis had queries mainly regarding drug alternatives while few asked about the dosage strengths or side effects (see Table 3). On the other hand it was quite pleasing to see the aspirations of people regarding the duties of pharmacist in which substantial majority $(90 \%, n=271)$ favoured that the pharmacist should be expert in medications and should know the adverse effects and interactions. Almost all of the respondents (96\%, $n=291$ ) believed that the pharmacist should always follow the medical practitioners' advice while preparing and dispensing the medications according to the prescriptions. Among these respondents, however, a sizable number of patients (40-60\%) signalled that they were ready to accept a pharmacist correcting a prescription if he or she finds error and that a pharmacist is more expert on drugs than a doctor. These results strongly 
Table 4

Patients' perception of pharmacist.

\begin{tabular}{|c|c|c|c|c|c|c|c|c|}
\hline \multirow[t]{2}{*}{ Questionnaire's items } & \multicolumn{4}{|c|}{ Respondents' responses ${ }^{\mathrm{a}}$} & \multicolumn{4}{|c|}{$P$ value $^{\mathrm{b}}$} \\
\hline & SA $n(\%)$ & A $n(\%)$ & $\mathrm{D} n(\%)$ & $\mathrm{SD} n(\%)$ & Age & Gender & Education & Occupation \\
\hline Pharmacists are health care professional just like physician and nurses. & $28(9.3)$ & $225(74.8)$ & $47(15.6)$ & $1(0.3)$ & 0.105 & 0.001 & 0.001 & 0.020 \\
\hline I am not completely sure what a pharmacist does besides counting pills. & $66(21.9)$ & $191(63.5)$ & $44(14.6)$ & $0(0)$ & 0.015 & 0.524 & 0.001 & 0.176 \\
\hline $\begin{array}{l}\text { Pharmacists need to be experts in medication and conflicts between } \\
\text { different drugs. }\end{array}$ & $131(43.5)$ & $139(46.2)$ & $31(10.3)$ & $0(0)$ & 0.179 & 0.139 & 0.106 & 0.009 \\
\hline Pharmacist's main job is to let me know how to use my medication. & $151(50.2)$ & $150(49.8)$ & $0(0)$ & $0(0)$ & 0.184 & 0.074 & 0.163 & 0.015 \\
\hline It's a pharmacist's job to follow my doctor's directions. & $140(46.5)$ & $147(48.8)$ & $14(4.7)$ & $0(0)$ & 0.200 & 0.120 & 0.015 & 0.041 \\
\hline $\begin{array}{l}\text { I regularly follow my pharmacist's advice when selecting medication for } \\
\text { minor illnesses } \\
\text { (like a cough, rash or upset stomach). }\end{array}$ & $81(26.9)$ & $150(49.8)$ & $62(20.6)$ & $8(2.7)$ & 0.105 & 0.138 & 0.005 & 0.119 \\
\hline $\begin{array}{l}\text { My pharmacist knows more about my medicine, its side effects and how to } \\
\text { use it than my doctor. }\end{array}$ & $24(8)$ & $95(31.6)$ & $139(46.2)$ & $43(14.3)$ & 0.220 & 0.205 & 0.128 & 0.059 \\
\hline Pharmacists are just business people who sell products I $n$ a pharmacy & $132(43.9)$ & $101(33.6)$ & $68(22.6)$ & $0(0)$ & 0.278 & 0.163 & 0.032 & 0.016 \\
\hline $\begin{array}{l}\text { My pharmacist can change my prescription if he founds errors in the } \\
\text { medication. }\end{array}$ & $42(14)$ & $133(44.2)$ & $109(36.2)$ & $17(5.6)$ & 0.491 & 0.362 & 0.001 & 0.028 \\
\hline I want my pharmacist to know me and my history. & $117(38.9)$ & $117(38.9)$ & $67(22.3)$ & $0(0)$ & 0.269 & 0.499 & 0.063 & 0.159 \\
\hline Willing to spend some time required by pharmacists for counselling. & $99(32.9)$ & $192(63.8)$ & $10(3.3)$ & $0(0)$ & 0.083 & 0.133 & 0.037 & 0.039 \\
\hline
\end{tabular}

a $\mathrm{SA}=$ Strongly Agree, $\mathrm{A}=$ Agree, $\mathrm{D}=$ Disagree, $\mathrm{SD}=$ Strongly Disagree.

b Chi-square value.

suggest that people in the society are quite willing to accept a pharmacist to play a proper functioning role, at least in a community setup. This viewpoint can further be supplemented by the facts that over $75 \%(n=234)$ of the respondents were willing to share their medication history with a pharmacist and to take advice from a pharmacist for minor illnesses which may involve the treatment with OTC drugs. Even more, almost $96 \%(n=291)$ of patients were willing to spend some time with their pharmacist for counselling. These results give high hopes for community pharmacists to exercise their responsibilities with minimal obstructions as far as public reception is concerned because the major roles of a pharmacist in a community setup seems to have good measure of acceptability in general public considering the present state of its practice in the country.

When it comes to choosing a pharmacy for regular prescription filling and purchasing of medicines, two factors came out the strongest based upon the patient's or respondents convenience, one being the discount $(100 \%, n=301)$ and other being the shortest travelling distance from home $(95 \%, n=287)$ especially for those people who were aged 40 and above $(100 \%, n=301)$. In contrast to these results, a study conducted in United States showed the provision of pharmaceutical care was the major influential factor among participants followed by personal attention from pharmacist. ${ }^{18}$ The reason of this variation could be due to the fact that the practice of pharmacy is well established in United States and people are more aware and they realize the importance of the services provided by pharmacists. Keeping the current scenario of community health care setup in mind, it was surprising to see that the other factors which were found to be complementary in selecting a pharmacy included availability of a pharmacists and his or her expertise (90\%, $n=270$ agreed for both the factors) who may entertain them rather than just being dealt by subordinates or technicians (who are usually employed to follow the directives of either a pharmacist or businessmen who would have been running pharmacy for years and have experience at least regarding OTC drugs; people usually know them personally). Around $85 \%$ ( $n=253$ ) of people voted in favour of the fact that pharmacists counselling could be a deciding factor and 70\% believed that good relationship with a pharmacist may influence positively towards selecting a particular pharmacy. However, as what has been observed from the preceding discussion regarding the scarcity of a qualified pharmacist and consequent perception of people about the role of a pharmacist, only $60 \%(n=212)$ people either agreed or strongly agreed to be influenced by the fact that pharmacist could tell them about the related side effects or answer as many question as they would like to ask about their medication. Over all its was observed that the most of the people, generally irrespective of gender, age, occupation and education; and despite knowing not much about pharmacist role and pharmacy being a profession, agreed to the fact that pharmacists do have a value in health care setup and welcomed various functions of community pharmacy to be practiced by qualified pharmacists. This study may be

Table 5

Factors influencing choice of pharmacy.

\begin{tabular}{|c|c|c|c|c|c|c|c|c|}
\hline \multirow[t]{2}{*}{ Questionnaire's items } & \multicolumn{4}{|c|}{ Respondents' responses ${ }^{a}$} & \multicolumn{4}{|c|}{$P$ value $^{\mathrm{b}}$} \\
\hline & SA $n(\%)$ & A $n(\%)$ & $\mathrm{D} n(\%)$ & $\mathrm{SD} n(\%)$ & Age & Gender & Education & Occupation \\
\hline Availability of pharmacist & $131(43.5)$ & $139(46.2)$ & $31(10.3)$ & $0(0)$ & 0.262 & 0.217 & 0.046 & 0.076 \\
\hline Location (nearer to house) & $115(38.2)$ & $172(57.1)$ & $14(4.7)$ & $0(0)$ & 0.485 & 0.289 & 0.063 & 0.159 \\
\hline $\begin{array}{c}\text { How well the pharmacist knows you and } \\
\text { your history (personal relationship). }\end{array}$ & $70(23.3)$ & $142(47.2)$ & $89(29.6)$ & $0(0)$ & 0.079 & 0.107 & 0.012 & 0.151 \\
\hline The expertise of the pharmacist. & $124(41.2)$ & $146(48.5)$ & $31(10.3)$ & $0(0)$ & 0.036 & 0.132 & 0.376 & 0.028 \\
\hline Discount. & $61(20.3)$ & $240(79.7)$ & $0(0)$ & $0(0)$ & 0.165 & 0.362 & 0.080 & 0.462 \\
\hline Counselling by trained pharmacists & $40(13.3)$ & $213(70.8)$ & $48(15.9)$ & $0(0)$ & 0.337 & 0.197 & 0.077 & 0.218 \\
\hline Inform me about related side effects/where & $27(9)$ & $149(49.5)$ & $125(41.5)$ & $0(0)$ & 0.156 & 0.115 & 0.282 & 0.030 \\
\hline
\end{tabular}

questions efficiently

\footnotetext{
a $\mathrm{SA}=$ Strongly Agree, $\mathrm{A}=$ Agree, $\mathrm{D}=$ Disagree, $\mathrm{SD}=$ Strongly Disagree.
}

b Chi-square value. 
supplemented with possible future research surveys on a larger scale to strengthen the conclusions drawn about the perception of general public regarding pharmacists, his role, and pharmacy services.

\section{Conclusion}

This study is the first of its kind conducted in an urban area of Pakistan where people's perception about community pharmacy practice was evaluated. It concludes that patients, especially living in the urban areas of Pakistan, in general have a positive perception of pharmacist. However, it is worth noticing and mentioning that besides people's primitive understanding about the profession and its community setup, they are quite welcoming and are keen to see advanced functions of pharmacy services be practiced in their community as observed from the various items of this study. This study tentatively explores room for pharmacy graduates to practice pharmacy at community scale and suggests that the communication gap between patients and pharmacists can be lessened by proactive involvement of pharmacists in community setup and only then a proper and adequate message could be conveyed to patients in particular and public in general.

\section{Conflicts of interest}

All authors have none to declare.

\section{References}

1. Khan MU. A new paradigm in clinical pharmacy teaching in Pakistan. Am J Pharm Educ. 2011;75:166.

2. Wirth F, Tabone F, Azzopardi LM, Gauci M, Zarb-Adami M, Serracino-Inglott A. Consumer perception of the community pharmacist and community pharmacy services in Malta. J Pharm Health Serv Res. 2010;1:189-194.
3. Assa-Eley M, Kimberlin CL. Using interpersonal perception to characterize pharmacists' and patients' perceptions of the benefits of pharmaceutical care. Health Commun. 2005; 17:41-56.

4. Liu MY, Jennings JP, Samuelson WM, Sullivan CA, Veltri JC. Asthma patients satisfaction with the frequency and content of pharmacist counseling. J Am Pharm Assoc. 1999;39:493-498.

5. Wiederholt JB, Rosowski PG. Antecedents of expectations for pharmacist information services measured in naturalistic settings. Mark Theor App. 1996;7:296.

6. Mackowiak JI, Manasse HR. Expectation vs. demand for pharmacy service. J Pharm Mark Manage. 1988;2:57-72.

7. Schommer JC. Ohio pharmacists' conceptual views and experiences regarding patient counselling. Drug Inf J. 1994;28:765-775.

8. Chewning B, Schommer JC. Increasing clients' knowledge of community pharmacists' roles. Pharm Res. 1996;13:1299-1304.

9. Perepelkin J. Public opinion of pharmacist and pharmacist prescribing. Can Pharm J. 2011;144:86-93.

10. Shah B, Chewning B. Conceptualizing and measuring pharmacist-patient communication: a review of published studies. Res Social Adm Pharm. 2006;2: $153-185$.

11. Wilbur K, Samah ELS, Mohammadi E. Patient perceptions of pharmacist roles in guiding self-medication of over-the-counter therapy in Qatar. Patient Prefer Adherence. 2010;4:87-93.

12. Vinod KR, Sandhya S. Effective tools of pharma counselling. J Young Pharm. 2009;1:90-93.

13. Schommer JC. Patients' expectation and knowledge of patient counselling services that are available from pharmacists. Am I Pharm Educ. 1997;61: 402-406.

14. Raosoft. An Online Sample Size Calculator; 2008 [cited 2013 Feb 5]. Available at: http://www.raosoft.com/samplesize.html.

15. Azhar H, Ibrahim MIM. Medication counselling and dispensing practices at community pharmacies: a comparative cross sectional study from Pakistan. Int J Clin Pharm. 2011;33:859-867.

16. Murtaza G, Ahmad M, Iqbal M, Khan SA, Ejaz M, Yasmin T. Pharmacy Education and Practice in Pakistan: a Guide to Further Development [cited 2013 Mar 2]. Available at: http://www.eczfakder.hacettepe.edu.tr/Arsiv/EskiDergiler/02 2010/02\%20makale.pdf.

17. Heinze C. Changing Perceptions: Strengthening the Value of Pharmacy through Advocacy. Pharmacy Times. Published online: August 1, 2008 [cited $2013 \mathrm{Mar}$ 2]. Available at: http://www.pharmacytimes.com/publications/career/2008/ Careers_2008-08/Careers_2008-08_8001.

18. Ried LD, Wang F, Young H, Awiphan R. Patients' satisfaction and their perception of the pharmacist. J Am Pharm Assoc. 1999;39:835-842. 